\title{
NONLINEAR MODELING OF ANNUAL RUNOFF OF MAIN RIVERS IN BELARUS
}

Aliaksandr Volchak ${ }^{1}$, Aleh Meshyk ${ }^{1}$, Sergey Parfomuk ${ }^{1}$, Yury Mazhayskiy ${ }^{2}$, Olga Chernikova ${ }^{3}$

${ }^{1}$ Brest State Technical University, Belarus; ${ }^{2}$ All-Russian Research Institute of Hydrotechnics and

Melioration named after A.N. Kostyakova, Russia; ${ }^{3}$ Academy of Law Management of the Federal

Penal Service of Russia, Russia

volchak@tut.by,omeshyk@gmail.com,parfom@mail.ru,director@mntc.pro,

chernikova_olga@inbox.ru

\begin{abstract}
The article investigates the problem of mathematical description of long-term fluctuations of river runoff, which is relevant for solving problems of modeling and forecasting in engineering hydrology. The description of the process of runoff fluctuations is based on the stochastic differential equations of OrshteinUhlenbeck and Fokker-Planck-Kolmogorov. A technique that makes it possible to apply low-parameter nonlinear dynamic models of river runoff has been developed. Mechanisms of the cyclicity of long-term fluctuations the Pripyat, Neman, West Dvina, Dnieper, and Berezina rivers are described. Comparison of the forecasting results according to the methodology developed by us showed better results than the modeling method using a simple Markov chain. The nonlinear model makes it possible to predict a series that has a correlation function similar to the original series with a shift of 4 or more years, and the Markov model gives good results only for an autocorrelation function with a shift of one year. The simulated series of annual runoff have statistical parameters that differ from the parameters of the original series within $\pm 5-10 \%$.
\end{abstract}

Keywords: stochastic hydrology, nonlinear modeling, river runoff, forecast.

\section{Introduction}

Recently, the problem of long-term fluctuations of river runoff has been widely studied. Runoff fluctuations have a pronounced cyclicality with possible positive or negative trends. Creation of deterministic models of runoff and artificial hydrological series makes it possible to solve predictive problems of engineering hydrology. For example, forecasting spring floods, natural disasters, taking into account current climatic fluctuations $[1 ; 2]$. In the second half of the last century research was carried out on the creation of deterministic models of the processes of river runoff formation using the methods of mathematical physics and their use in hydrological forecasts and calculations. However, the need for the development of new methods for the application of low-parameter nonlinear dynamic models of river runoff, which makes it possible to describe the physical mechanisms of the cyclicity of long-term fluctuations in river runoff, remains relevant [3-6]. The Soil and Water Assessment Tool (SWAT) is used to model water, sediment, and nutrient yield in a watershed using input data from GIS and the application of various farming, climate change, and land practices [7;8]. The Soil and Water Integrated Model (SWIM) is used to study climate-induced runoff changes, extreme flood analysis, agricultural production, and so on $[9 ; 10]$. The use of artificial intelligence methods as an approach to solving complex nonlinear problems and predicting lake levels has increased [11;12]

\section{Materials and methods}

Let $\bar{Q}$ be the average long-term water discharge, and $Q_{t}-$ the water discharge at time $t$. Then, taking $X_{t}=\left(Q_{t}-\bar{Q}\right) / \bar{Q}$, the process of long-term runoff fluctuations can be described using the following Orshtein-Uhlenbeck stochastic differential equation with continuous time $\mathrm{t}$ [13]

$$
d X_{t}=-k X_{t} d t+\sigma d W_{t},
$$

where $k^{-1}$ - relaxation time of river runoff;

$\sigma$ - intensity of "white noise";

$W_{t}-$ standard Wiener process.

The intensity of "white noise" is defined as $\sigma=C_{v} \sqrt{2 k}$, where $C_{v}$ is the coefficient of variation of the river runoff, and the coefficient $k$ is from the following relation $k=-\ln r$, where $r$ is the autocorrelation function of fluctuations in the river runoff.

Equation (1) corresponds to the Fokker-Planck-Kolmogorov equation

$$
\frac{\partial p}{\partial t}=\frac{\partial}{\partial x}(k x p)+\frac{\sigma^{2}}{2} \frac{\partial^{2} p}{\partial x^{2}}, \quad-\infty<x<\infty,
$$

DOI: 10.22616/ERDev.2021.20.TF012 
and the inverse equation has the form

$$
\frac{\partial}{\partial t} p(x, t / y, 0)=-k y \frac{\partial}{\partial y} p(x, t / y, 0)+\frac{1}{2} \sigma^{2} \frac{\partial^{2} p(x, t / y, 0)}{\partial y^{2}}, \quad-\infty<x<\infty,
$$

since the random fluctuations of the runoff are homogeneous in time, that means that the relation $p(x, t / y, 0)=p(x, 0 / y, t)$ holds.

Consider the following problem in stochastic hydrology. Let at the initial moment of time $t=0$ the runoff is equal to $Q$, and $Q_{*}$ is some fixed value of the runoff. It is required to determine the period of time during which the runoff value will be within $\left[Q_{*}, \infty\right)$. Let $T$ be the moment in time when the runoff value leaves the half-interval $\left[Q_{*}, \infty\right)$.

Then

$$
\operatorname{prob}(T \geq t)=G(Q, t) \quad G(Q, t)=\int_{Q_{*}}^{\infty} p(x, t / y, 0) d x .
$$

Integrating (3) from $Q_{*}$ to $\infty$ over $x$, we obtain

$$
\frac{\partial G(Q, t)}{\partial t}=-k Q \frac{\partial G(Q, t)}{\partial Q}+\frac{\sigma^{2}}{2} \frac{\partial^{2} G(Q, t)}{\partial Q^{2}} .
$$

The boundary conditions are determined proceeding from the absorption of the value of the function at $Q=Q_{*}$, as well as from the reflection at infinity, that is

$$
\left.G(Q, t)\right|_{Q=Q_{*}}=0,\left.\quad \frac{\partial G(Q, t)}{\partial Q}\right|_{Q=\infty}=0 .
$$

The average time to reach the boundary $Q_{*}$ is determined by the following relation

$$
T_{1}=-\int_{0}^{\infty} t \frac{\partial G(Q, t)}{\partial t} d t=\int_{0}^{\infty} G(Q, t) d t .
$$

Integrating (3) over $t$ from 0 to $\infty$ and taking into account that

$$
\int_{0}^{\infty} \frac{\partial G}{\partial t} d t=G(x, \infty)-G(x, 0)=-1,
$$

we obtain the following equation for

$$
T_{1} 1 \frac{1}{2} \sigma^{2} \frac{d^{2} T_{1}}{d Q^{2}}-k Q \frac{d T_{1}}{d Q}=-1 \text { at }\left.\frac{d T_{1}}{d Q}\right|_{Q=\infty}=0,\left.T_{1}(Q)\right|_{Q=Q_{*}}=0 .
$$

Introducing dimensionless quantities

$$
\theta_{1}=k T_{1}, \quad \xi=Q \sqrt{\frac{2 k}{\sigma^{2}}}=\frac{Q}{C_{v}}, \quad \xi_{*}=Q_{*} \sqrt{\frac{2 k}{\sigma^{2}}}=\frac{Q_{*}}{C_{v}},
$$

we get

$$
\frac{d^{2} \theta_{1}}{d \xi^{2}}-\xi \frac{d \theta_{1}}{d \xi}=-1,\left.\quad \frac{d \theta_{1}}{d \xi}\right|_{\xi=\infty}=0,\left.\quad \theta_{1}(\xi)\right|_{\xi=\xi_{*}}=0 .
$$

Integrating system (4) by the numerical method [14; 15], we get the results that are given in Table 1.

Solutions of equation (4)

\begin{tabular}{|c|c|c|c|c|c|c|c|c|c|c|c|c|}
\hline \multirow{2}{*}{$\xi_{*}$} & \multicolumn{10}{|c|}{$\boldsymbol{\xi}$} \\
\cline { 2 - 15 } & -2.5 & -2.0 & -1.5 & -1.0 & -0.5 & 0 & 0.5 & 1.0 & 1.5 & 2.0 & 2.5 & 3.0 \\
\hline-3.0 & 59.9 & 76.5 & 82.3 & 84.8 & 86.1 & 86.9 & 87.5 & 87.8 & 88.1 & 88.4 & 88.6 & 88.7 \\
\hline-2.5 & - & 16.6 & 22,4 & 24.9 & 26.2 & 27.0 & 27.5 & 27.9 & 28.2 & 28.4 & 28.6 & 28.8 \\
\hline-2.0 & - & - & 5.8 & 8.3 & 9.6 & 10.4 & 10.9 & 11.3 & 11.6 & 11.8 & 12.0 & 12.2 \\
\hline-1.5 & - & - & - & 2.5 & 3.8 & 4.6 & 5.1 & 5.5 & 5.8 & 6.0 & 6.2 & 6.4 \\
\hline-1.0 & - & - & - & - & 1.3 & 2.1 & 2.6 & 3.0 & 3.3 & 3.5 & 3.7 & 3.9 \\
\hline-0.5 & - & - & - & - & - & 0.7 & 1.3 & 1.7 & 2.0 & 2.2 & 2.4 & 2.6 \\
\hline 0 & - & - & - & - & - & - & 0.5 & 0.9 & 1.2 & 1.4 & 1.6 & 1.8 \\
\hline
\end{tabular}


Now, at the initial moment of time $t=0$, the runoff is equal to $Q$, and $Q_{*}$ is also some fixed value of the runoff, but already greater than the initial one. To determine the period of time during which the runoff value will be within $\left(\infty, Q_{*}\right]$, system (4) with modified initial conditions is used, that is,

$$
\left.G(Q, t)\right|_{Q=Q_{*}}=0,\left.\quad \frac{\partial G(Q, t)}{\partial Q}\right|_{Q=-\infty}=0 .
$$

Then we will have

$$
\frac{d^{2} \theta_{1}}{d \xi^{2}}-\xi \frac{d \theta_{1}}{d \xi}=-1,\left.\quad \frac{d \theta_{1}}{d \xi}\right|_{\xi=-\infty}=0,\left.\quad \theta_{1}(\xi)\right|_{\xi=\xi_{*}}=0 .
$$

The solution to the system (5) gives the same results as given in the Table 1, only the values $\xi$ and $\xi_{*}$ are taken with opposite signs.

\section{Results and discussion}

The above methodology for determining runoff changes was proposed for 5 main rivers of Belarus [16; 17]. The data were used for the period of instrumental observations in the following sections: the Pripyat River at Mozyr, the Neman River at Grodno, the West Dvina River at Vitebsk, the Dnieper River at Mogilev, and the Berezina River at Bobruisk (Fig. 1).

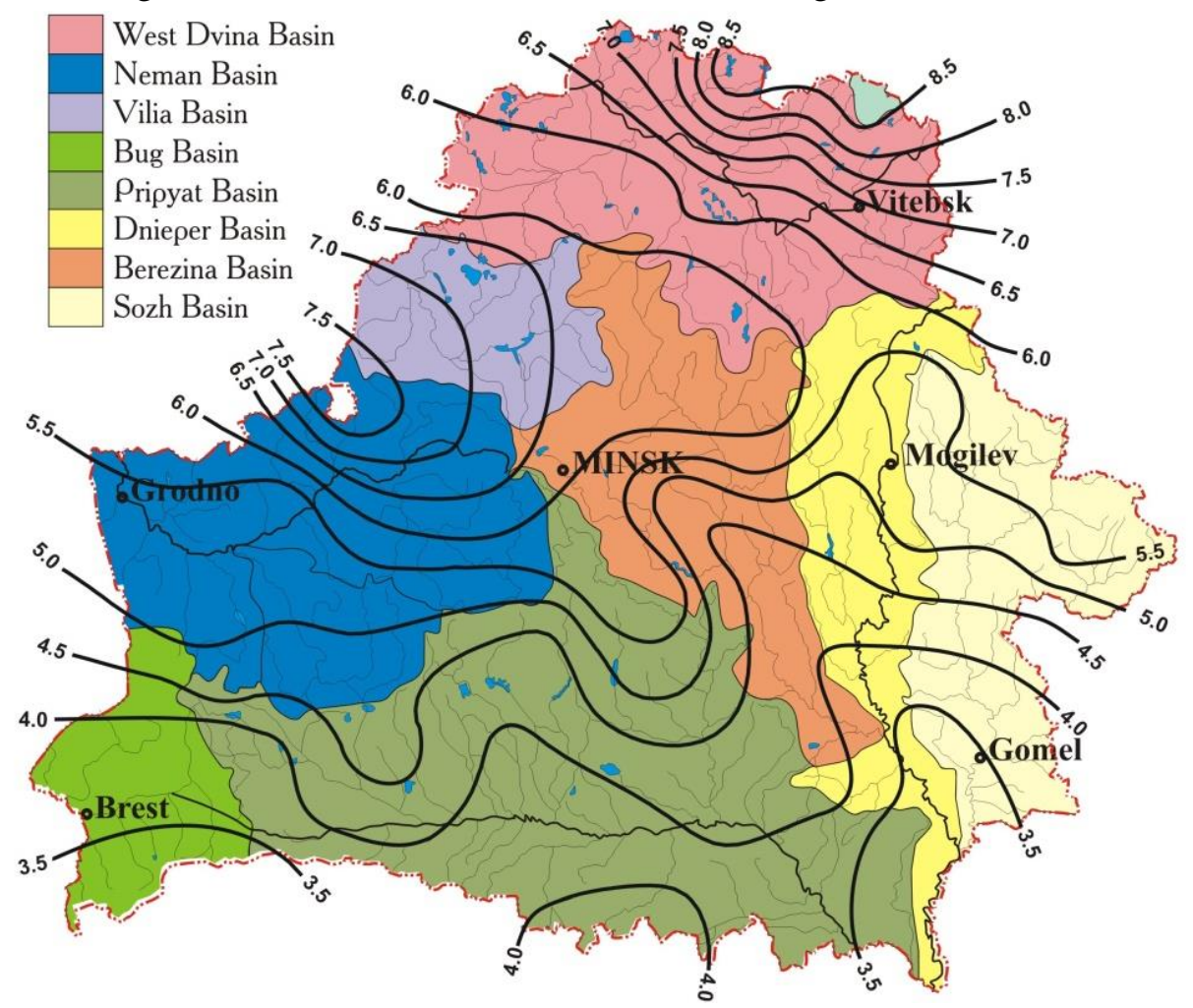

Fig. 1. Map of the mean annual river runoff in Belarus $(1956-2015), l \cdot\left(s^{\cdot} \mathbf{k m}^{2}\right)^{-1}[18]$

Let us consider as an example the calculation of the time of change in the values of the annual runoff of the Pripyat River at Mozyr. Table 2 shows the values of the main statistical parameters of the time series of the annual water discharge of the Pripyat River at Mozyr.

Table 2

\section{Main statistical parameters of the time series of the annual water discharge of the Pripyat River at Mozyr}

\begin{tabular}{|c|c|c|c|}
\hline $\boldsymbol{Q}_{\text {mean }}, \mathrm{m}^{3} \cdot \mathrm{s}^{-1}$ & $\sigma, \mathrm{m}^{3} \cdot \mathrm{s}^{-1}$ & $\boldsymbol{C}_{\boldsymbol{v}}$ & $r(1)$ \\
\hline 390 & 123 & 0.32 & 0.29 \\
\hline
\end{tabular}

The coefficient $k$ is determined by the formula $k=-\ln r=-\ln 0.29=1.24$. 
Let at the initial moment of time $t=0$ the runoff is $Q=640 \mathrm{~m}^{3} \cdot \mathrm{s}^{-1}$, and the fixed value of the runoff is $Q_{*}=200 \mathrm{~m}^{3} \cdot \mathrm{s}^{-1}$. Then $\xi$ is defined as the deviation of the initial runoff value from the annual average one in fractions of $C_{v}$, i.e.

$$
\xi=\frac{Q-Q_{\text {mean }}}{Q_{\text {mean }} \cdot C_{v}}=2 .
$$

Similarly, $\xi_{*}$ is defined as

$$
\xi_{*}=\frac{Q_{*}-Q_{\text {mean }}}{Q_{\text {mean }} \cdot C_{v}}=-1.5 .
$$

According to the values of $\xi$ and $\xi_{*}$ from Table 1 we find the value $\theta_{1}=6.0$. Then the period of time during which the runoff value will be in the range of $\left[Q_{*}, \infty\right)$ is defined as the quotient $\theta_{1}$ and $k$ :

$$
T_{1}=\frac{\theta_{1}}{k}=4.9 .
$$

The values of the dimensional time depending on the values of $Q$ and $Q_{*}$ are presented in Table 3.

Table 3

Values of the time of change in the annual runoff of the Pripyat River at Mozyr, years

\begin{tabular}{|c|c|c|c|c|c|c|c|c|c|c|c|}
\hline $\begin{array}{c}\text { Fixed runoff } \\
\text { value, } \mathbf{~ m}^{\mathbf{3}} \cdot \mathbf{s}^{-1}\end{array}$ & \multicolumn{10}{|c|}{ Runoff at the initial moment of time, $\mathbf{~ m}^{\mathbf{3}} \mathbf{s}^{\mathbf{- 1}}$} \\
\hline 200 & 0 & 250 & 300 & 350 & 400 & 450 & 500 & 550 & 600 & 650 & 700 \\
\hline 250 & 0.2 & 0 & 1.0 & 3.5 & 3.9 & 4.3 & 4.5 & 4.7 & 4.9 & 5.0 & 5.2 \\
\hline 300 & 0.4 & 0.2 & 0 & 0.7 & 1.1 & 1.4 & 1.7 & 1.9 & 2.1 & 2.2 & 2.3 \\
\hline 350 & 0.7 & 0.5 & 0.3 & 0 & 0.4 & 0.8 & 1.0 & 1.2 & 1.4 & 1.5 & 1.7 \\
\hline 400 & 1.0 & 0.9 & 0.7 & 0.4 & 0 & 0.3 & 0.6 & 0.8 & 0.9 & 1.1 & 1.2 \\
\hline 450 & 1.6 & 1.4 & 1.2 & 0.9 & 0.5 & 0 & 0.3 & 0.5 & 0.6 & 0.8 & 0.9 \\
\hline 500 & 2.4 & 2.1 & 1.9 & 1.7 & 1.3 & 0.8 & 0 & 0.2 & 0.4 & 0.5 & 0.6 \\
\hline 550 & 3.6 & 3.4 & 3.2 & 2.9 & 2.6 & 2.0 & 1.3 & 0 & 0.2 & 0.3 & 0.4 \\
\hline 600 & 5.9 & 5.7 & 5.5 & 5.2 & 4.8 & 4.3 & 3.6 & 2.3 & 0 & 0.1 & 0.3 \\
\hline 650 & 10.7 & 10.5 & 10.3 & 10.0 & 9.7 & 9.1 & 8.4 & 7.1 & 4.8 & 0 & 0.1 \\
\hline 700 & 22.0 & 21.8 & 21.6 & 21.4 & 21.0 & 20.5 & 19.7 & 18.4 & 16.1 & 11.3 & 0 \\
\hline
\end{tabular}

Let us calculate the values of the dimensional time required for modeling the hydrological series for the remaining four sections. Table 4 shows the values of the main statistical parameters of the time series of annual water discharge for four sections.

\section{Main statistical parameters of the time series of the annual water discharge} of the cross sections for the main rivers of Belarus

\begin{tabular}{|c|c|c|c|c|}
\hline River - Section & $\boldsymbol{Q}_{\text {mean }} \mathbf{~ m}^{\mathbf{3}} \cdot \mathbf{s}^{\mathbf{1}}$ & $\boldsymbol{\sigma} \mathbf{~ m}^{\mathbf{3}} \cdot \mathbf{s}^{\mathbf{1}}$ & $\boldsymbol{C}_{\boldsymbol{v}}$ & $\boldsymbol{r ( \mathbf { 1 } )}$ \\
\hline Neman River at Grodno & 197 & 35.5 & 0.18 & 0.16 \\
\hline West Dvina River at Vitebsk & 226 & 61.6 & 0.27 & 0.31 \\
\hline Dnieper River at Mogilev & 143 & 34.9 & 0.24 & 0.22 \\
\hline Berezina River at Bobruisk & 119 & 22.9 & 0.19 & 0.05 \\
\hline
\end{tabular}

Dimensional time values depending on $Q$ and $Q_{*}$ values are presented for sections of the Neman River at Grodno, the West Dvina River at Vitebsk, the Dnieper River at Mogilev, the Berezina River at Bobruisk in Tables 5-8.

Modeling of artificial hydrological series for sections of practically unlimited duration (more than 1000 years) is carried out using the results of Tables 3, 5-8, as well as using a simple Markov chain [19].

At the initial moment of time, a random value of the supply is simulated by means of a drawing, then the value of the discharge is determined according to the theoretical curve of supply predefined for the time series, which is plotted on the time scale.

The second modeled value of the supply makes it possible to determine the next value of the runoff. Having the values of runoff at the initial and final moments of time, according to Table 3 , the nearest 
whole time interval is found, after which the second runoff value is plotted on the scale. Further, the next value of the supply is taken, according to which the value of the runoff is determined and the time interval plotted on the scale. Similarly, the simulation continues until the end of the time scale is reached, after which the process starts over, but when filling the scale, if the abscissa values coincide, priority is given to the value found at earlier stages of modeling. The first free value on the time scale is used to determine the runoff value at the previous moment in time, and from it - the discharge value at the current moment using a simple Markov chain [19]

$$
x_{i+1}=1+r\left(x_{i}-1\right)+F_{i+1} C_{v} \sqrt{1-r^{2}},
$$

where $x_{i+1}-$ value of the modular coefficient of the annual runoff volume in the $(i+1)$-th year;

$r$ - autocorrelation coefficient;

$x_{i}$ - value of the modular coefficient of the annual runoff volume in the $i$-th year;

$C_{v}$ - coefficient of variation.

The value of the function $F$ is determined by the following formula

$$
F(x)=\frac{1}{\sqrt{2 \pi}} \int_{-\infty}^{x} e^{-\frac{z^{2}}{2}} d z .
$$

The obtained value of the annual runoff at the current moment is the initial one for subsequent modeling. The process continues until the entire scale is filled. The number of stages is limited and cannot exceed the duration of the modeled hydrological series.

Table 5

Values of the time of change in the annual runoff of the Neman River at Grodno, years

\begin{tabular}{|c|c|c|c|c|c|c|c|c|c|c|c|}
\hline Fixed runoff & \multicolumn{10}{|c|}{ Runoff at the initial moment of time, $\mathbf{~ m}^{\mathbf{3}} \mathbf{s}^{\mathbf{- 1}}$} \\
\cline { 2 - 15 } $\mathbf{~}^{\mathbf{3}} \cdot \mathbf{s}^{-\mathbf{1}}$ & 100 & 120 & 140 & 160 & 180 & 200 & 220 & 240 & 260 & 280 & 300 \\
\hline 100 & 0 & 16.9 & 21.7 & 23.5 & 24.3 & 24.7 & 25.0 & 25.3 & 25.4 & 25.5 & 25.6 \\
\hline 120 & 0.1 & 0 & 4.7 & 6.5 & 7.3 & 7.8 & 8.1 & 8.3 & 8.4 & 8.5 & 8.7 \\
\hline 140 & 0.3 & 0.1 & 0 & 1.7 & 2.6 & 3.0 & 3.3 & 3.5 & 3.7 & 3.8 & 3.9 \\
\hline 160 & 0.4 & 0.3 & 0.2 & 0 & 0.8 & 1.2 & 1.6 & 1.8 & 1.9 & 2.1 & 2.2 \\
\hline 180 & 0.6 & 0.5 & 0.4 & 0.2 & 0 & 0.5 & 0.8 & 1.0 & 1.1 & 1.3 & 1.4 \\
\hline 200 & 1.0 & 0.9 & 0.7 & 0.6 & 0.3 & 0 & 0.3 & 0.5 & 0.7 & 0.8 & 0.9 \\
\hline 220 & 1.5 & 1.4 & 1.3 & 1.1 & 0.9 & 0.5 & 0 & 0.2 & 0.4 & 0.5 & 0.6 \\
\hline 240 & 2.5 & 2.4 & 2.3 & 2.1 & 1.9 & 1.5 & 1.0 & 0 & 0.2 & 0.3 & 0.4 \\
\hline 260 & 4.8 & 4.7 & 4.6 & 4.4 & 4.2 & 3.8 & 3.3 & 2.3 & 0 & 0.1 & 0.2 \\
\hline 280 & 11.5 & 11.4 & 11.3 & 11.1 & 10.9 & 10.6 & 10.0 & 9.0 & 6.7 & 0 & 0.1 \\
\hline 300 & 38.0 & 37.9 & 37.8 & 37.6 & 37.4 & 37.0 & 36.5 & 35.5 & 33.2 & 26.5 & 0 \\
\hline
\end{tabular}

Table 6

Values of the time of change in the annual runoff of the West Dvina River at Vitebsk, years

\begin{tabular}{|c|c|c|c|c|c|c|c|c|c|c|c|}
\hline \multirow{2}{*}{$\begin{array}{c}\text { Fixed runoff } \\
\text { value, } \mathbf{~}^{\mathbf{3}} \cdot \mathbf{s}^{-\mathbf{1}}\end{array}$} & \multicolumn{10}{|c|}{ Runoff at the initial moment of time, $\mathbf{~}^{\mathbf{3}} \mathbf{s}^{\mathbf{- 1}}$} \\
\hline 100 & 100 & 125 & 150 & 175 & 200 & 225 & 250 & 275 & 300 & 325 & 350 \\
\hline 125 & 0 & 5.1 & 7.5 & 8.8 & 9.6 & 10.2 & 10.6 & 10.9 & 11.1 & 11.3 & 11.4 \\
\hline 150 & 0.2 & 0 & 2.4 & 3.8 & 4.6 & 5.1 & 5.5 & 5.8 & 6.0 & 6.2 & 6.4 \\
\hline 175 & 0.3 & 0.2 & 0 & 1.3 & 2.1 & 2.7 & 3.1 & 3.4 & 3.6 & 3.8 & 4.0 \\
\hline 200 & 0.6 & 0.4 & 0.2 & 0 & 0.8 & 1.4 & 1.8 & 2.0 & 2.3 & 2.5 & 2.6 \\
\hline 225 & 0.8 & 0.7 & 0.5 & 0.3 & 0 & 0.5 & 0.9 & 1.2 & 1.5 & 1.6 & 1.8 \\
\hline 250 & 1.2 & 1.0 & 0.9 & 0.7 & 0.4 & 0 & 0.4 & 0.7 & 0.9 & 1.1 & 1.3 \\
\hline 275 & 1.7 & 1.6 & 1.4 & 1.2 & 0.9 & 0.5 & 0 & 0.3 & 0.5 & 0.7 & 0.9 \\
\hline 300 & 2.5 & 2.3 & 2.1 & 1.9 & 1.6 & 1.3 & 0.8 & 0 & 0.2 & 0.4 & 0.6 \\
\hline 325 & 3.7 & 3.5 & 3.4 & 3.1 & 2.9 & 2.5 & 2.0 & 1.2 & 0 & 0.2 & 0.4 \\
\hline 350 & 5.9 & 5.7 & 5.6 & 5.3 & 5.1 & 4.7 & 4.2 & 3.4 & 2.2 & 0 & 0.2 \\
\hline & 10.4 & 10.2 & 10.0 & 9.8 & 9.5 & 9.1 & 8.6 & 7.9 & 6.6 & 4.5 & 0 \\
\hline
\end{tabular}


Values of the time of change in the annual runoff of the Dnieper River at Mogilev, years

\begin{tabular}{|c|c|c|c|c|c|c|c|c|c|c|c|}
\hline \multirow{2}{*}{$\begin{array}{c}\text { Fixed runoff } \\
\text { value, } \mathbf{~ m}^{\mathbf{3}} \cdot \mathbf{s}^{-1}\end{array}$} & \multicolumn{10}{|c|}{ Runoff at the initial moment of time, $\mathbf{~ m}^{\mathbf{3}} \mathbf{s}^{\mathbf{1}}$} \\
\hline 80 & 0 & 2.6 & 3.9 & 4.6 & 5.1 & 5.4 & 5.7 & 5.9 & 6.0 & 6.2 & 6.3 \\
\hline 95 & 0.1 & 0 & 1.3 & 2.0 & 2.5 & 2.8 & 3.1 & 3.3 & 3.4 & 3.6 & 3.7 \\
\hline 110 & 0.3 & 0.2 & 0 & 0.7 & 1.2 & 1.5 & 1.8 & 2.0 & 2.1 & 2.3 & 2.4 \\
\hline 125 & 0.5 & 0.4 & 0.2 & 0 & 0.5 & 0.8 & 1.0 & 1.2 & 1.4 & 1.5 & 1.6 \\
\hline 140 & 0.8 & 0.7 & 0.5 & 0.3 & 0 & 0.3 & 0.6 & 0.8 & 0.9 & 1.0 & 1.1 \\
\hline 155 & 1.2 & 1.1 & 0.9 & 0.7 & 1.4 & 0 & 0.2 & 0.4 & 0.6 & 0.7 & 0.8 \\
\hline 170 & 1.8 & 1.7 & 1.5 & 1.3 & 1.0 & 0.6 & 0 & 0.2 & 0.3 & 0.5 & 0.6 \\
\hline 185 & 2.9 & 2.7 & 2.6 & 2.3 & 2.0 & 1.6 & 1.0 & 0 & 0.1 & 0.3 & 0.4 \\
\hline 200 & 4.8 & 4.7 & 4.5 & 4.3 & 4.0 & 3.6 & 3.0 & 1.9 & 0 & 0.1 & 0.2 \\
\hline 215 & 9.0 & 8.9 & 8.7 & 8.5 & 8.2 & 7.8 & 7.2 & 6.2 & 4.2 & 0 & 0.1 \\
\hline 230 & 20.0 & 19.9 & 19.7 & 19.5 & 19.2 & 18.8 & 18.2 & 17.2 & 15.2 & 11.0 & 0 \\
\hline
\end{tabular}

Table 8

Values of the time of change in the annual runoff of the Berezina River at Bobruisk, years

\begin{tabular}{|c|c|c|c|c|c|c|c|c|c|c|c|}
\hline Fixed runoff & \multicolumn{10}{|c|}{ Runof at the initial moment of time, $\mathbf{~ m}^{\mathbf{3}} \mathbf{s}^{\mathbf{- 1}}$} \\
\cline { 2 - 14 }${\text { value, } \mathbf{~ m}^{\mathbf{3}} \cdot \mathbf{s}^{\mathbf{1}}}^{-1}$ & 80 & 90 & 100 & 110 & 120 & 130 & 140 & 150 & 160 & 170 & 180 \\
\hline 80 & 0 & 1.1 & 1.7 & 20 & 2.2 & 24 & 2.5 & 2.6 & 2.7 & 2.7 & 2.8 \\
\hline 90 & 0.1 & 0 & 0.6 & 0.9 & 1.1 & 1.3 & 1.4 & 1.5 & 1.6 & 1.6 & 1.7 \\
\hline 100 & 0.2 & 0.1 & 0 & 0.3 & 0.6 & 0.7 & 0.8 & 0.9 & 1.0 & 1.0 & 1.1 \\
\hline 110 & 0.3 & 0.2 & 0.1 & 0 & 0.2 & 0.4 & 0.5 & 0.6 & 0.7 & 0.7 & 0.8 \\
\hline 120 & 0.5 & 0.4 & 0.3 & 0.2 & 0 & 0.2 & 0.3 & 0.4 & 0.4 & 0.5 & 0.5 \\
\hline 130 & 0.7 & 0.6 & 0.5 & 0.4 & 0.2 & 0 & 0.1 & 0.2 & 0.3 & 0.3 & 0.4 \\
\hline 140 & 1.1 & 1.0 & 0.9 & 0.8 & 0.6 & 0.4 & 0 & 0.1 & 0.2 & 0.2 & 0.3 \\
\hline 150 & 1.7 & 1.6 & 1.5 & 1.4 & 1.3 & 1.0 & 0.6 & 0 & 0.1 & 0.1 & 0.2 \\
\hline 160 & 3.0 & 2.9 & 2.8 & 2.7 & 2.5 & 2.3 & 1.9 & 1.3 & 0 & 0.1 & 0.1 \\
\hline 170 & 6.0 & 5.9 & 5.8 & 5.7 & 5.5 & 5.3 & 4.9 & 4.3 & 3.0 & 0 & 0.1 \\
\hline 180 & 14.4 & 14.3 & 14.2 & 14.1 & 13.9 & 13.7 & 13.4 & 12.7 & 11.4 & 8.4 & 0 \\
\hline
\end{tabular}

Modeling the series of annual runoff by the indicated method gives acceptable results. The simulated series of annual water discharges using a simple Markov chain and a nonlinear method for the calculated sections have statistical parameters that differ from the parameters of the original series within $\pm 5-10 \%$. The values of the correlation functions for the original and modeled series for the Pripyat River at Mozyr are given in Table 9.

Table 9

Values of the statistical parameters of the initial and modeled time series of the annual water discharge of the Pripyat River at Mozyr

\begin{tabular}{|l|c|c|c|c|c|c|c|c|}
\hline \multirow{2}{*}{ Time series } & \multicolumn{7}{|c|}{ Statistical parameters } \\
\cline { 2 - 10 } & $\begin{array}{c}Q_{\text {mean }}, \\
\mathrm{m}^{3} \cdot \mathrm{s}^{-1}\end{array}$ & $\begin{array}{c}\sigma, \\
\mathrm{m}^{3} \cdot \mathrm{s}^{-1}\end{array}$ & $C_{v}$ & $r(t-1)$ & $r(t-4)$ & $r(t-5)$ & $r(t-10)$ & $r(t-24)$ \\
\hline Initial & 390 & 123 & 0.32 & 0.290 & 0.105 & 0.223 & 0.100 & 0.175 \\
\hline $\begin{array}{l}\text { Modeled by simple } \\
\text { Markov chain }\end{array}$ & 388 & 117 & 0.30 & 0.303 & 0.005 & -0.048 & -0.036 & 0.035 \\
\hline $\begin{array}{l}\text { Modeled by } \\
\text { nonlinear method }\end{array}$ & 399 & 137 & 0.34 & -0.040 & 0.102 & 0.099 & 0.192 & 0.165 \\
\hline
\end{tabular}

Using the apparatus of regression-correlation analysis, a complex Markov model was obtained with a shift of up to 50 years in annual fluctuations in water discharge, depending on $r(t-1), r(t-4), r(t-$ $5), r(t-10)$ and $r(t-24)$. The research has shown that modeling an artificial hydrological series by a simple Markov chain gives good results only for an autocorrelation function with a shift of one year, 
since this parameter is included in the modeling. A nonlinear model allows predicting a series with a correlation function similar to the initial series with a shift of 4 or more years.

\section{Conclusions}

The application of stochastic differential equations for the description and forecasting of long-term fluctuations in the annual runoff is proposed. The problem of stochastic hydrology of predicting the value of river runoff for 5 main rivers of Belarus is solved, and a method for modeling artificial hydrological series is proposed, which gives better results for predicting the "distant" correlation than the modeling method using a simple Markov chain. The simulated series of annual runoff have statistical parameters that differ from the parameters of the original series within $\pm 5-10 \%$. The research results can be applied in calculating and forecasting long-term fluctuations in river runoff of unexplored and poorly studied rivers in Belarus.

\section{References}

[1] Volchak A. A., Meshyk A. P., Sheshka M. M. [et al.]. Floods on the territory of Polesie. Procedia Engineering. 162, 2016, pp. 91-97, DOI: 10.1016/j.proeng.2016.11.020.

[2] Volchak A., Parfomuk S. Assessment of changes in the Viliya River runoff in the territory of Belarus. Limnological Review, Vol. 18, No. 4, 2018, pp. 185-196.

[3] Liu D. A rational performance criterion for hydrological model. Journal of Hydrology. 590, 125488, 2020. DOI: $10.1016 / \mathrm{j} . j h y d r o l .2020 .125488$.

[4] Farmer W. H., Vogel R. M. On the deterministic and stochastic use of hydrologic models, Water Resour. Res., 52, 2016, pp. 5619-5633. DOI: 10.1002/2016WR019129.

[5] Bond N. R., Kennard M. J. Prediction of hydrologic characteristics for ungauged catchments to support hydroecological modeling. Water Resour. Res., 53, 2017, pp. 8781-8794. DOI: 10.1002/2017WR021119.

[6] Pande S., Moayeri M. Hydrological interpretation of a statistical measure of basin complexity. Water Resour. Res., 54, 2018, pp. 7403-7416. DOI: 10.1029/2018WR022675.

[7] Bosch N., Allan J., Dolan D., Han H., Richards R. Application of the soil and water assessment tool for six watersheds of Lake Erie: model parameterization and calibration. Journal of Great Lakes Research, 37, 2011, pp. 268-271.

[8] Schiefer E., Petticrew E., Immell R., Hassab M., Sonderegger D. Land use and climate change impacts on lake sedimentation rates in western Canada. Anthropocene 3, 2013, pp. 61-71.

[9] Stagl J., Hattermann F. Impacts of climate change on the hydrological regime of the Danube River and its tributaries using an ensemble of climate scenarios. Water, 7, 2015, pp. 6139-6172.

[10] Wortmann M., Krysanova V., Kundzewicz Z., Su B., Li X. Assessing the influence of the Merzbacher Lake outburst floods on discharge using the hydrological model SWIM in the Aksu headwaters. Kyrgyzstan/NW China. Hydrological Processes, 28, 2014, pp. 6337-6350.

[11] Shaghaghi S., Bonakdari H., Gholami A., Ebtehaj I., Zeinolabedini M. Comparative analysis of GMDH neural network based on genetic algorithm and particle swarm optimization in stable channel design. Applied Mathematics and Computation, 313, 2017, pp. 271-286.

[12]Zaji A., Bonakdari, H., Gharabaghi, B. Reservoir water level forecasting using group method of data handling. Acta Geophysica, 66 (4), 2018, pp. 717-730.

[13] Naydenov V. I. Nonlinear models of river runoff fluctuations/Naydenov V. I., Shveikina V. I. // Water resources. Moscow, T. 29. - No. 1. 2002, pp. 62-67.

[14] Panteleev A.V., Yakimova A.S., Bosov A.V. Ordinary differential equations in examples and tasks: Tutorial. - Moscow: Higher school, 2001.- 376 p.

[15] Prokopenya A.N., Chichurin A.V. Application of the Mathematica system to the solution of ordinary differential equations: Textbook. - Minsk: BSU, 1999 .- 265 p.

[16] Loginov V.F. Stochastic modeling of various types of runoff of the main rivers of Belarus using nonlinear models/V.F. Loginov, A.A. Volchek, An. A. Volchek, S. I. Parfomuk // Reports of the National Academy of Sciences of Belarus. - T. 50. - No. 6. - 2006, pp. 96-100.

[17] Volchek A. A. Quantitative assessment of the impact of a changing climate on the water regime of rivers in Belarus/A. A. Volchek, V. E. Valuev, O. Meshik, S. I. Parfomuk, D. N. Dashkevich// 
Bulletin of the Brest State Technical University. No. 2 (86): Water management construction, heat power engineering and geoecology, 2014, pp. 3-8.

[18] Volchak A., Kirvel I., Parfomuk S. The changes of water resources in Belarus. Geography in the face of the modern world challenges. Krakow, 2016, pp. 63-72.

[19] Svanidze G.G. Mathematical modeling of hydrological series. - Leningrad: Gidrometeoizdat, 1977, $296 \mathrm{p}$. 